\title{
Laboratory assessment of the influence of rice straw mulch size on soil loss
}

\author{
João L. M. P. de Lima, Lara Santos, Babar Mujtaba, and M. Isabel P. de Lima \\ MARE - Marine and Environmental Sciences Centre, Department of Civil Engineering, Faculty of Science and Technology \\ of the University de Coimbra, 3030-788 Coimbra, Portugal
}

Correspondence: João L. M. P. de Lima (plima@ dec.uc.pt)

Received: 19 December 2018 - Revised: 1 March 2019 - Accepted: 18 March 2019 - Published: 26 April 2019

\begin{abstract}
Application of crop residues (mulch) over the soil surface is a common practice to control soil erosion and promote infiltration. This laboratory study aimed at investigating the effect of different rice straw mulch sizes on runoff and sediment transport. The experimental runs were conducted using a soil flume of adjustable slope and a rainfall simulator, considering bare soil and three different soil covers: 1,2 and $5 \mathrm{tha}^{-1}$ application rates, for three sizes of rice straw mulch $(10,30$ and $200 \mathrm{~mm})$. The experimental results showed that for the same mulch application rate (by weight), the smaller mulch sizes (i.e. high surface coverage percentage) presented less soil loss. For example, $90 \%$ soil loss reduction was achieved for smaller sizes of rice straw mulch and $80 \%$ for the bigger size. The results of this study are an important contribution to the understanding of the soil loss process in small basins and to the definition of relevant soil conservation measures, at the plot/field scale.
\end{abstract}

\section{Introduction}

Soil erosion induced by rainfall is a serious environmental threat to ecosystems and water bodies. Various factors influence soil loss, such as soil type, topography, rainfall characteristics, wind, vegetation cover and human activities. The influence of these factors is well documented in field studies (Dunne et al., 1991; Ekwue and Harrilal, 2010; Dunkerley, 2011) and laboratory studies (Römkens et al., 2001; de Lima et al., 2002, 2003, 2012; de Lima and Singh, 2003). Soil conservation measures are vital for sustainable agriculture, and these can be achieved by applying different types of mulches such as crop residues, leaf litter, woodchips, biological geotextiles and rock fragments (Ruy et al., 2006; Smets et al.,
2008; Ruiz-Sinoga et al., 2010; Prats et al., 2017). Particularly, organic crop residues are often used as mulch due to their high cost effectiveness, where different application rates could be considered to better fit field conditions.

Mulch protects soil from rainfall induced erosion by decreasing runoff and soil loss and increasing infiltration (e.g. Foltz and Dooley, 2003; Yanosek et al., 2006). Also, mulch contributes to improve the physical and chemical properties of soil (Mulumba and Lal, 2008; Jordán et al., 2010), namely related to temperature, evaporation and water content (Cook et al., 2006; Dahiya et al., 2007). However, its effectiveness is affected by several factors such as mulch type, size, rate, cover percentage and spatial uniformity distribution (Poesen et al., 1994; Smets et al., 2008; Jordán et al., 2010; Choi et al., 2012; Gholami et al., 2013; Prats et al., 2017).

Distinct types of mulches have different degrees of impact on the reduction of soil erosion and runoff. For example, Fernández et al. (2011) studied straw mulch, wood-chip mulch and cut-shrub barriers in Galicia (NW Spain) as post-fire soil erosion control measures, and Mulumba and Lal (2008) and Jordán et al. (2010) applied wheat straw mulch rate of $4 \mathrm{tha}^{-1}$ for increasing porosity and $8 \mathrm{tha}^{-1}$ for enhancing available water capacity, moisture retention and aggregate stability. Also, several researchers have demonstrated the importance of ground cover percentage (e.g. Pannkuk and Robichaud, 2003; Yanosek et al., 2006) through laboratory experiments.

Studies regarding the impact of mulch size, for the same application rate, on ground cover percentage, runoff and soil loss are scarce. A single laboratory study, in our knowledge, has been conducted by Poesen and Lavee (1991) in which inorganic polystyrene mulch was used to study the impact 

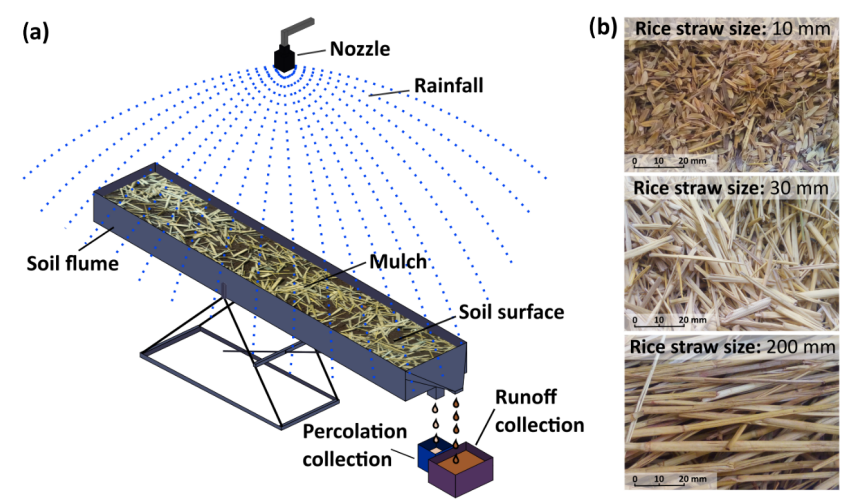

Figure 1. Laboratory setup: (a) schematic representation; and (b) rice straw mulch sizes used.

of mulch size on interrill runoff and sediment yield. Four different sizes $(30,59,117$ and $223 \mathrm{~mm})$ in square shapes were tested at $30,49,70$ and 88 surface coverage percentages (i.e. by area) and the authors concluded that runoff and soil loss decreased with the decrease in mulch size for a given surface cover percentage. In view of this, the aim of this study was to understand the effect of the size of rice straw mulch applied on the soil surface on runoff and soil loss, through systematic laboratory experiments using a soil flume under simulated rainfall. Results can contribute to the increased insight into the soil loss process and response in small basins and to the definition of relevant soil conservation measures, at the plot/field scale.

\section{Materials and Methodology}

\subsection{Laboratory setup}

An experimental setup comprised of a rainfall simulator, a soil flume with adjustable slope and a runoff sampling system was used (Fig. 1a).

\subsubsection{Rainfall characteristics}

The rainfall simulator was equipped with a downward oriented $3.58 \mathrm{~mm}$ orifice diameter nozzle. The sprinkler is fixed on a connecting rod in a stand placed $2.20 \mathrm{~m}$ above the flume surface. A hydraulic system maintains the uniformity of the pressure at the nozzle, as described in Isidoro and de Lima (2015). The steady state operating pressure at the nozzle was 1.4 bar. Water from a constant head reservoir is used for sprinkling with the help of a submerged pump, using city tap water with characteristics shown in Table 1 . This table was added because of the known influence of water characteristics on infiltration. Experiments were conducted at mean rainfall intensity of $84 \mathrm{~mm} \mathrm{~h}^{-1}$, during $15 \mathrm{~min}$, which is comparable to a 20 year return event at central region of Portugal (Brandão et al., 2001). The uniformity coefficient was calcu-
Table 1. Main physical and chemical characteristics of the water used in the soil flume experiments (Águas de Coimbra, 2016).

\begin{tabular}{llrr}
\hline Parameters & Units & Minimum & Maximum \\
\hline Conductivity & $\mu \mathrm{S} \mathrm{cm}^{-1}$ at $20^{\circ} \mathrm{C}$ & 85 & 127 \\
$\mathrm{pH}$ & - & 6.5 & 7.8 \\
Turbidity & $\mathrm{NTU}$ & $<0.5$ & 1.7 \\
$\mathrm{O}_{2}$ & $\mathrm{mg} \mathrm{L}^{-1}$ & $<1.0$ & 3.7 \\
Total hardness & $\mathrm{mgCaCO}_{3} \mathrm{~L}^{-1}$ & $<17$ & 81 \\
\hline
\end{tabular}

Table 2. Main physical characteristics of the soil used in the soil flume experiments (de Lima et al., 2003).

\begin{tabular}{lll}
\hline Parameters & Units & Values \\
\hline Sand content & $\%$ & 79 \\
Silt content & $\%$ & 10 \\
Clay content & $\%$ & 11 \\
Bulk density & $\mathrm{kg} \mathrm{m}^{-3}$ & 1100 \\
Soil depth & $\mathrm{mm}$ & 62 \\
Colour & - & brownish \\
\hline
\end{tabular}

lated according to Christiansen (1942) and was around $50 \%$. Mean raindrop diameters and velocities were calculated from measurements with a Laser Precipitation distrometer in three places on the soil flume surface (middle, top and bottom) and were, respectively, $\sim 0.8 \mathrm{~mm}$ and $\sim 2.6 \mathrm{~m} \mathrm{~s}^{-1}$.

\subsubsection{Flume and soil characteristics}

The flume consists of metal sheets and is $2.7 \mathrm{~m}$ long, $0.3 \mathrm{~m}$ wide and $0.1 \mathrm{~m}$ deep. The soil used (Table 2) is a sandy loam with a composition of quartz, feldspars, quartzite, muscovite and clay minerals, which was collected from fluvial deposits from the right bank of river Mondego, near the vicinity of Coimbra (e.g. de Lima et al., 2003). This soil was sieved through a $15 \mathrm{~mm}$ mesh in order to remove vegetation residues and stones. After that, soil was placed in the soil flume in successive thin layers, up to a height of $62 \mathrm{~mm}$ over the iron mesh flume bottom, which was covered with a geotextile rug in order to have free percolation of downward soil water flow. Geometrically, the soil surface was a plane. Experiments were conducted at $20 \%$ slope gradient.

\subsubsection{Mulch characteristics}

The mulch used was rice straw (Oryza sativa L. ssp. japonica), most cultivated rice species in the agricultural fields of Lower-Mondego Valley, near Coimbra, Portugal. This rice variety can achieve a plant height of $\sim 0.76 \mathrm{~m}$ and a rice grain size of $7 \mathrm{~mm}$. The rice straw mulch was subdivided into three sizes (Fig. 1b): 10, 30 and $200 \mathrm{~mm}$ (corresponding to D50, see Fig. 2). Longer stripes of rice straw were cut manually to obtain $200 \mathrm{~mm}$ long stripes whereas, crop shredder was used 


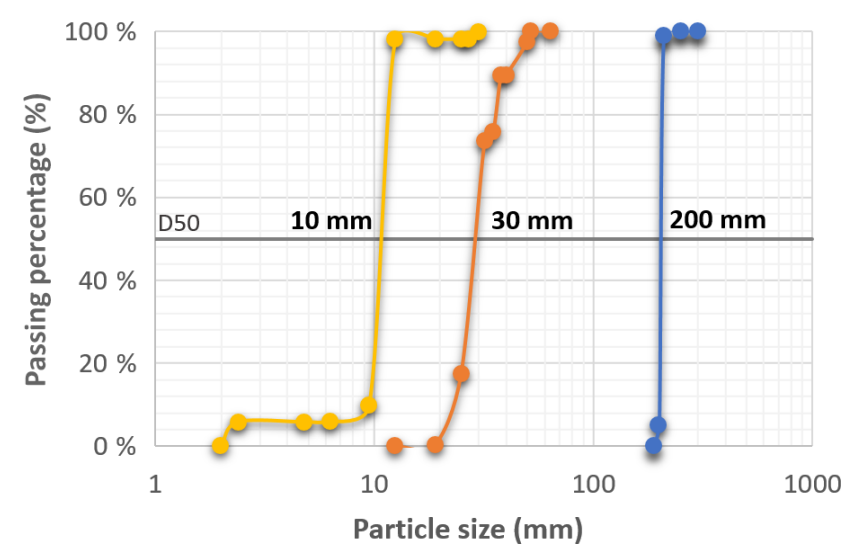

Figure 2. Particle size distribution of the rice straw mulch used in the experiments. D50 is used in the text as a reference for the 10, 30 and $200 \mathrm{~mm}$ mulch sizes.

to obtain $30 \mathrm{~mm}$ stripes and rice grain husk was used to obtain $10 \mathrm{~mm}$ sizes in length, as shown in Fig. 1b. Absorption capacity of each mulch size was obtained by placing $100 \mathrm{~g}$ of given size of dry mulch on soil flume at $20 \%$ slope covered with impermeable sheet and simulating a 15 min rain event of $84 \mathrm{~mm} \mathrm{~h}^{-1}$. Absorption capacity were determined as:

Absorption capacity $(\%)=\frac{w_{\text {wet }}-w_{\text {dry }}}{w_{\text {dry }}} \times 100$

where $w_{\text {wet }}$ is weight of mulch after rainfall event; $w_{\text {dry }}$ is weight of mulch before start of 15 min rainfall event.

Under rainfall the mulch capacity to absorb water is greater for the longer stripes of rice straws $(\sim 70 \%$ by weight) and lower for the 10 and $30 \mathrm{~mm}$ (respectively with $25 \%$ and $55 \%$ ). Experiments were conducted for 1, 2 and $5 \mathrm{tha}^{-1}$ mulch application rates. For each rate and given size, mulch was applied uniformly over the whole soil surface area $\left(0.81 \mathrm{~m}^{2}\right)$ of the flume.

\subsection{Experimental procedure}

A total of 9 combinations of mulch application rates and mulch sizes along with bare soil condition were tested for $20 \%$ slope gradient, as shown in Table 3. Each scenario was repeated three times, with a total of 30 experimental runs. Before the first experimental run on bare soil, soil was saturated gently using a hose connected to tap water until ponding started to occur and then, left to air dry for $45 \mathrm{~min}$ before the experiment started. This procedure aimed to commence the experiment at soil moisture corresponding approximately to field capacity. For the other experimental runs, conducted for bare soil and mulch scenarios, the top layer of the soil (roughly $5 \mathrm{~mm}$ ) was removed and replaced by a dry layer of soil. This ensured the presence of somewhat similar content of silt and clay at the top layer of soil which might have been washed away during the previous experiments. After that, the same procedure to acquire field capacity was conducted. The manual procedure of replacing the soil on the flume and wetting the soil before the simulated rainfall event is responsible for the high standard deviation observed in Table 3. For each mulch application rate, the experimental runs were conducted in sequence, for the different mulch sizes: 200, 30 and $10 \mathrm{~mm}$.

Photographs of mulch covered soil surface were taken at the downstream end of the soil flume before and after each experimental run (Fig. 3). The respective mulch cover percentage was obtained through image processing of these photographs, using MATLAB ${ }^{\circledR}$, for all three mulch sizes and applications rates. The image processing algorithm performed the image segmentation, using Otsu's threshold method (Mathworks, 2017). This image processing algorithm identified the mulch with respect to soil surface in photographs $(1024 \times 768$ pixels $)$ by converting them into black (soil surface) and white (mulch) single image by their brightness threshold values. After that, the areas of white and black portions in the image were evaluated in terms of pixels and then, these areas were estimated in $\mathrm{mm}^{2}$ based on a known width $(300 \mathrm{~mm})$ of measurement window as reference.

Each experimental run was conducted for a 15 min rainfall duration. A total of six samples of runoff volume were collected during $10 \mathrm{~s}$ each at the downstream end of the soil flume. These collected runoff samples were oven dried for $24 \mathrm{~h}$ at $80^{\circ} \mathrm{C}$ in order to obtain sediment loss.

\section{Results}

\subsection{Runoff response}

All runoff hydrographs presented almost similar behaviour, for all mulch application rates $\left(1,2\right.$ and $\left.5 \mathrm{tha}^{-1}\right)$, regardless of the mulch size (Fig. 4a). An approximate steady state condition (e.g. constant discharge) was obtained, 3-4 min after the start of the experiments. However, it is noticeable that runoff initiation times of all mulch scenarios were significantly higher than that of bare soil (25 s), as shown in Fig. 4a. As the mulch rate increased, runoff initiation time was further delayed. This pattern was similarly observed by Yanosek et al. (2006) who found that time to runoff was delayed with increase in cover level $(30 \%, 50 \%$ and $70 \%)$ corresponding to wood strand application rates of 4.0, 7.7 and $11.9 \mathrm{tha}^{-1}$, respectively.

Total runoff volumes of mulch scenarios were normally less than bare soil scenario, for all three mulch rates (Fig. 5a) and Table 3. This reduction of runoff and increase of runoff initiation time can be attributed to the ability of straw mulch pieces to absorb water and increase infiltration as observed by several researchers (e.g. Choi et al., 2012; Liu et al., 2012; Gholami et al., 2013). However, it should be noted that, since soil moisture was approximately at field capacity in all cases, infiltration was low which suggests that decrease in runoff volume might have been affected more by the different mulch 
Table 3. Mulch surface coverage, total runoff, total soil loss and ratio between soil loss for mulch cover and bare soil conditions. Average values and standard deviation (between brackets) are for three repetitions.

\begin{tabular}{|c|c|c|c|c|c|c|c|}
\hline Scenario & $\begin{array}{l}\text { Mulch rate } \\
\left(\mathrm{tha}^{-1}\right)\end{array}$ & $\begin{array}{r}\text { Mulch size } \\
(\mathrm{mm})\end{array}$ & $\begin{array}{r}\text { Mulch weight } \\
(\mathrm{g})\end{array}$ & $\begin{array}{r}\text { Surface coverage } \\
(\%)\end{array}$ & $\begin{array}{r}\text { Total runoff } \\
(\mathrm{L})\end{array}$ & $\begin{array}{l}\text { Total soil } \\
\text { loss }(\mathrm{g})\end{array}$ & $\begin{array}{l}\text { Soil loss ratio: } \\
\text { mulch cover vs. bare } \\
\text { soil conditions }(\%)\end{array}$ \\
\hline 2 & & 200 & 84 & $27.6( \pm 1.7)$ & $13.80( \pm 2.90)$ & $236.1( \pm 191.7)$ & 62 \\
\hline 3 & 1 & 30 & 84 & $29.8( \pm 3.9)$ & $14.18( \pm 1.33)$ & $98.0( \pm 65.7)$ & 26 \\
\hline 6 & 2 & 30 & 168 & $44.6( \pm 10.5)$ & $13.97( \pm 1.65)$ & $81.1( \pm 93.6)$ & 21 \\
\hline 7 & & 10 & 168 & $51.3( \pm 3.2)$ & $14.28( \pm 0.90)$ & $52.3( \pm 43.0)$ & 14 \\
\hline 8 & & 200 & 420 & $50.0( \pm 4.4)$ & $12.32( \pm 1.34)$ & $84.0( \pm 61.0)$ & 22 \\
\hline 9 & 5 & 30 & 420 & $59.3( \pm 1.8)$ & $12.99( \pm 0.94)$ & $36.0( \pm 13.1)$ & 10 \\
\hline
\end{tabular}

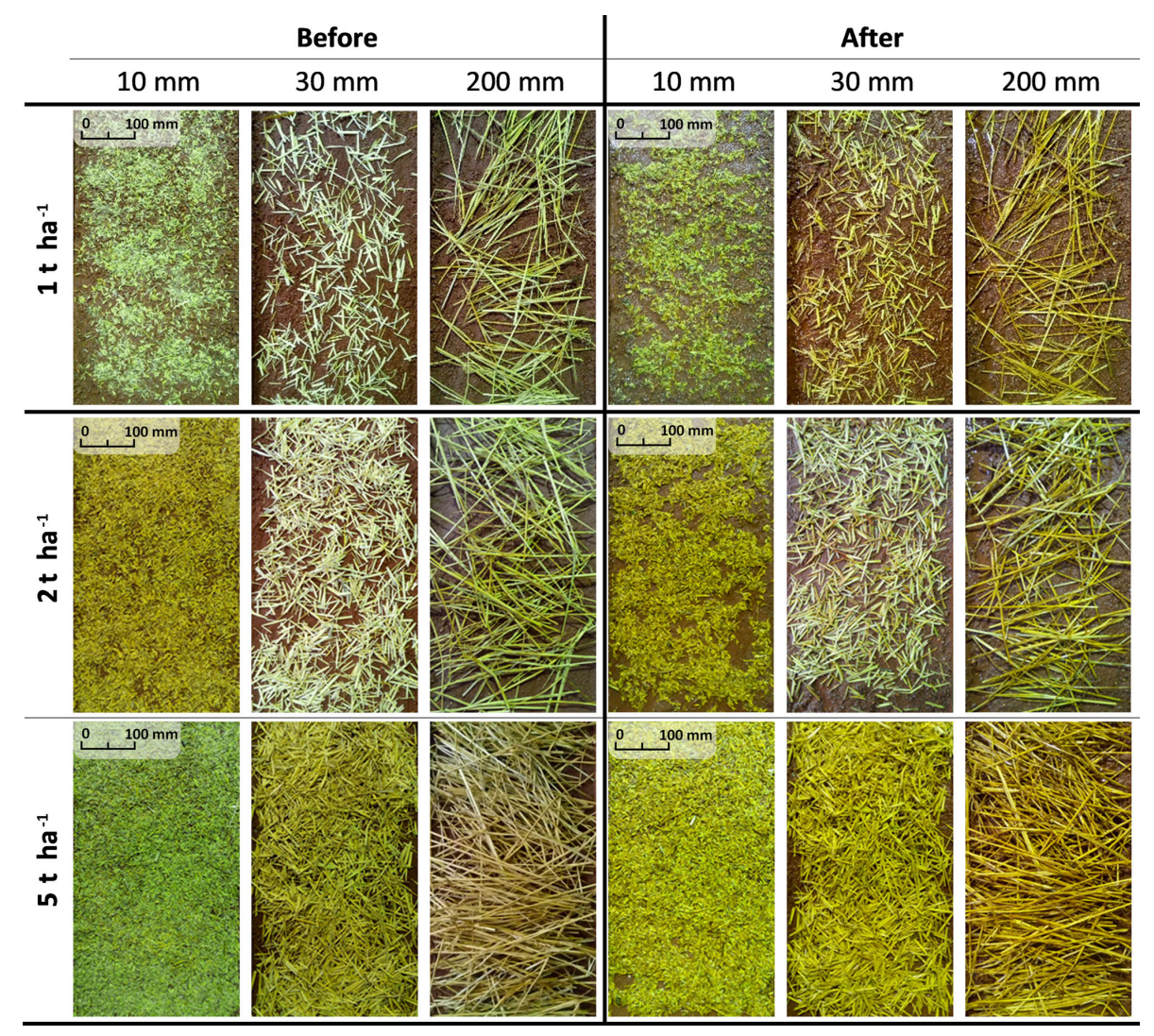

Figure 3. Photos of the soil surface covered with rice straw mulch for 1,2 and 5 tha $^{-1}$ mulch cover application rates and different mulch sizes (10, 30 and $200 \mathrm{~mm}$ ), before and after the experimental runs. Soil flume border wall effect is visible.

sizes' absorption capacities. As absorption capacity of rice straw mulch increased with increase in its size, runoff volume decreased for all three application rates as shown in Fig. 5. On the contrary, Poesen and Lavee (1991), found that runoff volume decreased with decrease in mulch size $(30,59,117$ and $223 \mathrm{~mm}$ ) of thick polystyrene square strips for a given percentage surface cover. In this case, this happened since the synthetic mulch cut into regular-shaped elements was impermeable to water; in our experiments the characteristics of the natural mulch (size, shape, thickness and porosity) interacted with intercepted rain. 

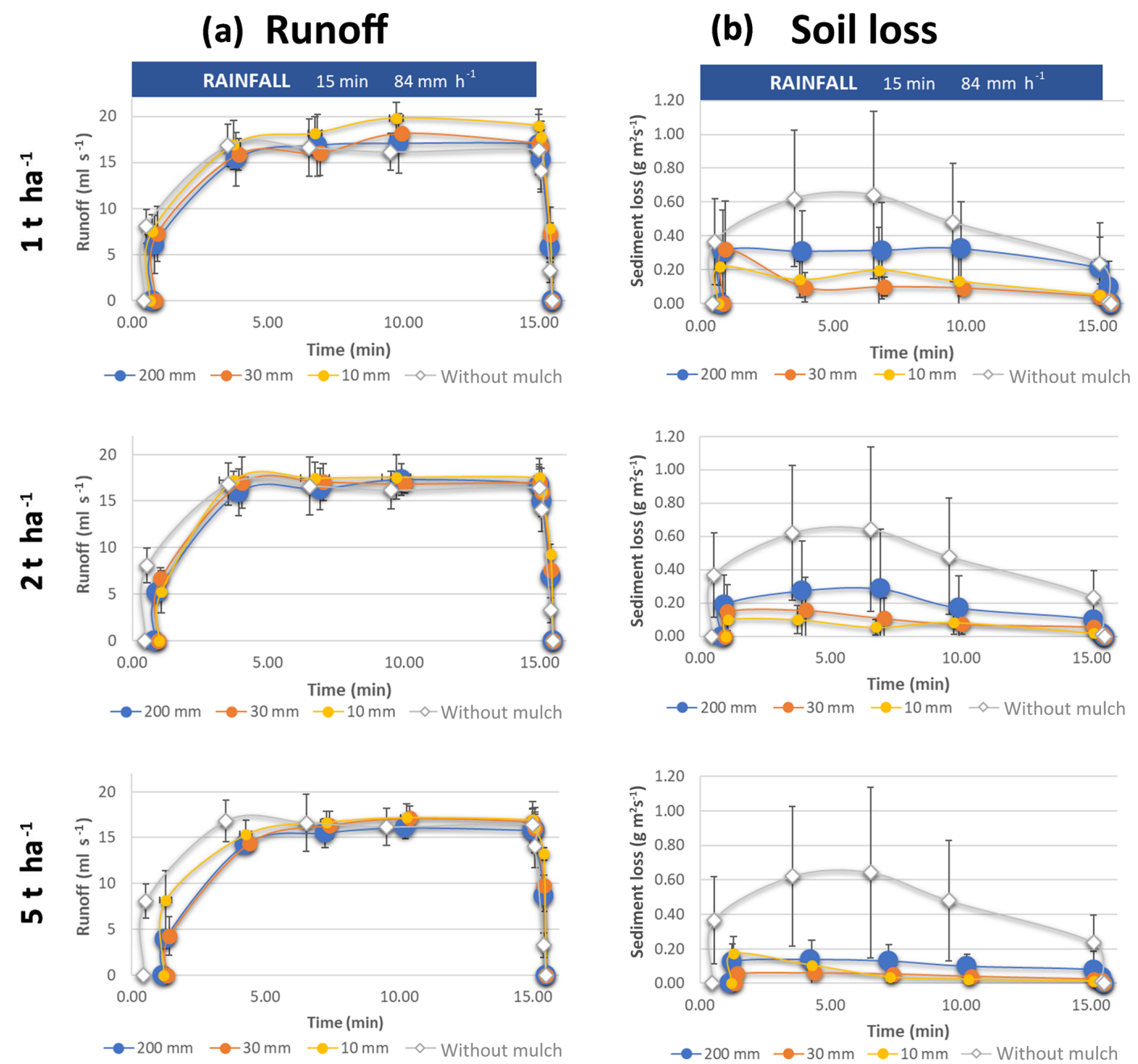

Figure 4. Response to constant intensity simulated rainfall: (a) runoff hydrographs and (b) sediment loss graphs, with average values and standard deviation bars (3 repetitions).

Pannkuk and Robichaud (2003) observed somewhat similar trend to our case when Granitic soil treated with Douglas Fir needles of $26.1 \mathrm{~mm}$ in length pieces produced lesser runoff than the same soil treated with Ponderosa pine needles of $165.3 \mathrm{~mm}$ in length, at all three $(15 \%, 40 \%$ and $70 \%)$ cover amounts. Also, in our case, as the mulch size increased, surface coverage percentage decreased as shown in Fig. 6a. This may suggest that reduction of runoff was not only dependent on soil coverage, but also on mulch characteristics (type, application rate, absorption capacity, size, etc.) and soil characteristics.

\subsection{Soil loss response}

In all mulch treated and bare soil scenarios, sediment loss was due to splash and sheet erosion (no rill formation was observed). The sedimentographs for bare soil and for all combinations of mulch sizes and application rates are presented in Fig. 4b. The mulch application has significantly decreased sediment loss (Figs. 4b, 5b). The higher the mulch application rate, the lesser the soil loss observed (Figs. 4b, 5b). For example, for $200 \mathrm{~mm}$ mulch size and 1,2 and $5 \mathrm{tha}^{-1}$ application rates (Table 3), the total soil loss reached $62 \%$, $42 \%$ and $22 \%$ of that found for bare soil conditions, respectively (soil loss reduces also with a decrease in mulch size for each application rate). This behaviour has been observed by several researchers (e.g. Pannkuk and Robichaud, 2003; Yanosek et al., 2006; Montenegro et al., 2013).

Figure $5 \mathrm{~b}$ suggests that the smaller the mulch size, the more effective is the decrease of soil loss for a given mulch application rate. This trend is also clear in Fig. 6c. Smaller mulch sizes were more prominent in reducing soil loss mainly because their surface coverage percentages were significantly higher as shown in Fig. 6a and Table 3. 
(a) Runoff
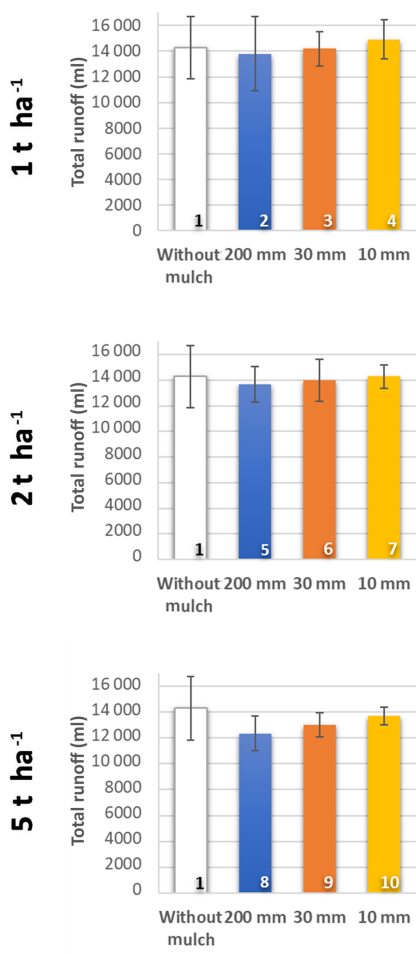

(b) Soil loss
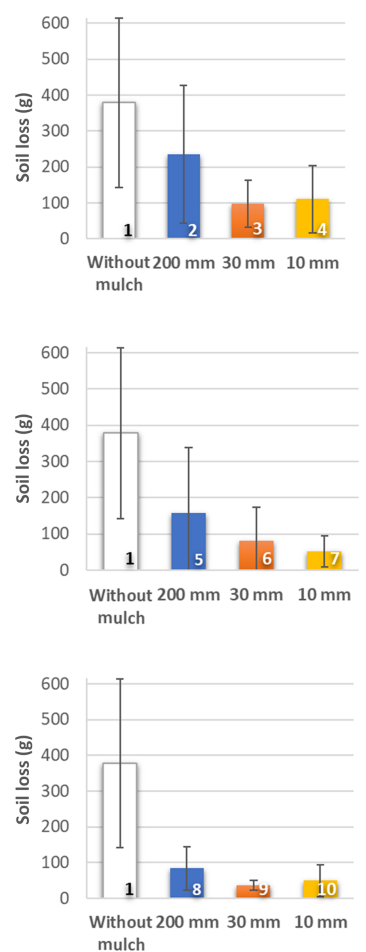

Figure 5. Response to constant intensity simulated rainfall: total (a) runoff and (b) soil loss for each scenario (bare soil and nine combinations of mulch size and application rates, see Table 3). Average and standard deviation bars are for 3 repetitions.

\section{Conclusions}

This paper addressed the effect of the size of rice straw mulch applied on the soil surface on runoff and soil loss. As expected and reported by few, for a given mulch size, runoff and soil loss decreased with increasing mulch application rate. Also, runoff initiation time increased with mulch application in comparison to bare soil scenarios for all mulch application rates $\left(1,2\right.$ and 5 tha $\left.^{-1}\right)$. With respect specifically to mulch size, the following major conclusion could be drawn:

1. Mulch size affected more soil loss than runoff;

2. For the tested rice straw application rates (by weight), runoff volume decreased with increasing mulch size mainly because of differences in the amount of water absorbed by mulch of different sizes;

3. For a given mulch application rate, soil loss reduction was higher for smaller than for bigger mulch sizes. $90 \%$ soil loss reduction was achieved for smaller sizes of rice straw mulch and $80 \%$ for the bigger size.

Considering all three mulch application rates (i.e. 1, 2 and $5 \mathrm{tha}^{-1}$ ), the application of rice straw mulch size of $30 \mathrm{~mm}$
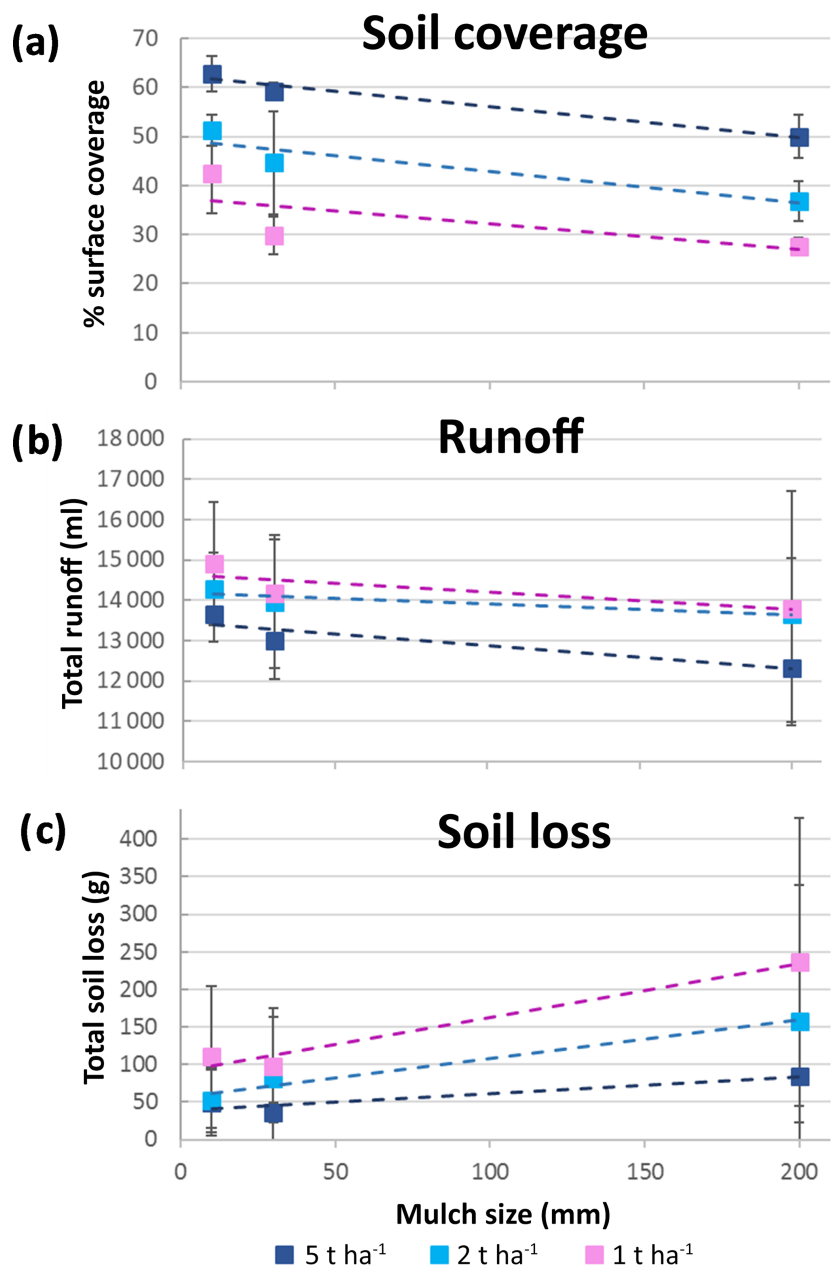

Figure 6. Response to different rice straw mulch sizes and application rates: (a) percentage of soil surface coverage by mulch, (b) total runoff, and (c) total soil loss as a function of mulch size, for 10, 30 and $200 \mathrm{~mm}$, and for 3 application rates. Average and standard deviation bars are for 3 repetitions.

was found to mitigate soil erosion more strongly, and to be less prone to be removed by runoff than the $10 \mathrm{~mm}$ size, on steeper and longer slopes or higher overland flow discharges.

It should be noted that results are specifically for rice straw mulch, although it is believed that the same general behaviour will be also observed for other mulch types. In fact, other mulch types (e.g. forest wood chips), topographic gradients (e.g. steeper and milder slopes), rainfall characteristics (e.g. intensity, drop size distributions) and antecedent moisture conditions (only field capacity soil moisture conditions were used to guarantee identical initial soil moisture conditions for all tests) should be tested. Also, by using image processing software changes in mulch coverage could be detected between images collected before and after rainfall events (e.g. mulch drift or shift downslope).

Although the results were found for small-plot scale laboratory conditions (i.e. using a soil flume and simulated rain- 
fall), which consensually means that they should mainly be used for comparative studies, the increased understanding of the runoff and soil loss response to different mulch applications of rice straw can contribute to inform soil conservation measures at larger scales. Ultimately, the behaviour found might be taken into consideration for the runoff and soil loss modelling at the small basin scale.

Data availability. No data sets were used in this article.

Author contributions. JLMPdL was responsible for the conceptualisation of the study, data interpretation and final review; LS and BM were responsible for conducting the laboratory tests, data acquisition and analysis and for writing the original manuscript; MIPdL was responsible for data analysis and interpretation and review.

Competing interests. The authors declare that they have no conflict of interest.

Special issue statement. This article is part of the special issue "Innovative monitoring techniques and modelling approaches for analysing hydrological processes in small basins". It is a result of the 17th Biennial Conference ERB 2018, Darmstadt, Germany, 1114 September 2018.

Acknowledgements. This work was supported by Project HIRT "Modelling surface hydrologic processes based on infrared thermography at local and field scales" (PTDC/ECM-HID/4259/2014POCI-01-0145-FEDER-016668), funded by FCT, Portugal and FEDER.

Review statement. This paper was edited by Britta Schmalz and reviewed by three anonymous referees.

\section{References}

Águas de Coimbra: Quality control of water intended for human consumption, Municipality of Coimbra, Boavista supply area, 2nd Semester 2016, Technical report, Coimbra, Portugal, 2016 (in Portuguese).

Brandão, C., Rodrigues, R., and Costa, J. P.: Analysis of extreme phenomena. Intense rainfall in Mainland Portugal. DSRH-INAG, Instituto da Água, Lisbon, Portugal, 2001 (in Portuguese).

Choi, J., Shin, M. H., Yoon, J. S., and Jang, J. R.: Effect of rice straw mulch on runoff and NPS pollution discharges from a vegetable field, in: Soil and water engineering, International Conference of Agricultural Engineering - CIGR-AgEng 2012: Agriculture and engineering for healthier live, Valencia, Spain, 8-12 July, 1465, 2012.
Christiansen, J. E.: Irrigation by sprinkling, California Agricultural Experiment Station Bulletin, 670, University of California, Berkeley, CA, 1942.

Cook, H. F., Valdes, G. S. B., and Lee, H. C.: Mulch effects on rainfall interception, soil physical characteristics and temperature under Zea mays L., Soil Till. Res., 91, 227-235, 2006.

Dahiya, R., Ingwersen, J., and Streck, T.: The effect of mulching and tillage on the water and temperature regimes of a loess soil: Experimental findings and modeling, Soil Till. Res., 96, 52-63, 2007.

de Lima, J. L. M. P. and Singh, V. P.: Laboratory experiments on the influence of storm movement on overland flow, Phys. Chem. Earth, 28, 277-282, 2003.

de Lima, J. L. M. P., Singh, V. P., Barreira, I. M., and de Lima, M. I. P.: Laboratory experiments on the influence of storm direction on soil loss from sloping areas, in: Surface Water Hydrology, edited by: Singh, V. P., Al-Rashid, M., and Sherif, M. M., A.A. Balkema Publishers, Swets and Zeitlinger, Lisse, the Netherlands, 405416, 2002.

de Lima, J. L. M. P., Singh, V. P., and de Lima, M. I. P.: The influence of storm movement on water erosion: storm direction and velocity effects, Catena, 52, 39-56, 2003.

de Lima, J. L. M. P., Carvalho, S. C. P., and de Lima, M. I. P.: Rainfall simulator experiments on the importance of when rainfall burst occurs during storm events on runoff and soil loss, Zeitschrift für Geomorphologie, 57, 91-109, 2012.

Dunkerley, D.: Effects of rainfall intensity fluctuations on infiltration and runoff: rainfall simulation on dryland soils, Fowlers Gap, Australia, Hydrol. Process., 26, 2211-2224, 2011.

Dunne, T., Zhang, W., and Aubry, B. F.: Effects of Rainfall, Vegetation, and Microtopography on Infiltration and Runoff, Water Resour. Res., 27, 2271-2285, 1991.

Ekwue, E. I. and Harrilal, A.: Effect of soil type, peat, slope, compaction effort and their interactions on infiltration, runoff and raindrop erosion of some Trinidadian soils, Biosyst. Eng., 105, 112-118, 2010.

Fernández, C., Vega, J. A., Jiménez, E., and Fonturbel, T.: Effectiveness of three post-fire treatments at reducing soil erosion in Galicia (NW Spain), Int. J. Wildland Fire, 20, 104-114, 2011.

Foltz, R. B. and Dooley, J. H.: Comparison of erosion reduction between wood strands and agricultural straw, American Society of Agricultural and Biological Engineers, 46, 1389-1396, 2003.

Gholami, L., Sadeghi, S. H. R., and Homaee, M.: Straw mulching effect on splash erosion, runoff and sediment yield from eroded plots, Soil Sci. Soc. Am. J., 77, 268-278, 2013.

Isidoro, J. M. G. P. and de Lima, J. L. M. P.: Hydraulic system to ensure constant rainfall intensity (over time) when using nozzle rainfall simulators, Hydrol. Res., 46, 705-710, https://doi.org/10.2166/nh.2015.087, 2015.

Jordán, A., Zavala, L. M., and Gil, J.: Effects of mulching on soil physical properties and runoff under semi-arid conditions in southern Spain, Catena, 81, 77-85, 2010.

Liu, Y., Taoa, Y., Wana, K. Y., Zhanga, G. S., Liub, D. B., Xiongb, G. Y., and Chena, F.: Runoff and nutrient losses in citrus orchards on sloping land subjected to different surface mulching practices in the Danjiangkou Reservoir area of China, Agric. Water Manage., 110, 34-40, 2012. 
Mathworks: Image Segmentation - MATLAB and Simulink, available at: https://www.mathworks.com/discovery/ image-segmentation.html (last access: 4 June 2018), 2017.

Montenegro, A. A. A., Abrantes, J. R. C. B., de Lima, J. L. M. P., Singh, V. P., and Santos, T. E. M.: Impact of mulching on soil and water dynamics under intermittent simulated rainfall, Catena, 109, 139-149, 2013.

Mulumba, L. N. and Lal, R.: Mulching effects on selected soil physical properties, Soil Till. Res., 98, 106-111, 2008.

Pannkuk, C. D. and Robichaud, P. R.: Effectiveness of needle cast at reducing erosion after forest fires, Water Resour. Res., 39, 1333, https://doi.org/10.1029/2003WR002318, 2003.

Poesen, J. W. and Lavee, H.: Effects of size and incorporation of synthetic mulch on runoff and sediment yield from interrills in a laboratory study with simulated rainfall, Soil Till. Res., 21, 209223, 1991

Poesen, J. W., Torri, D., and Bunte, K.: Effects of rock fragments on soil erosion by water at different spatial scales: a review, Catena, 23, 141-166, 1994.

Prats, S. A., Abrantes, J. R., Crema, I. P., Keizer, J. J., and de Lima, J. L. M. P.: Runoff and soil erosion mitigation with sieved forest residue mulch strips under controlled laboratory conditions, Forest Ecol. Manag., 396, 102-112, 2017.
Römkens, M. J. M., Helming, K., and Prasad, S. N.: Soil erosion under different rainfall intensities, surface roughness, and soil water regimes, Catena, 46, 103-123, 2001.

Ruiz-Sinoga, J. D., Romero-Diaz, A., Ferre-Bueno, E., and Martínez-Murillo, J. F.: The role of soil surface conditions in regulating runoff and erosion processes on a metamorphic hillslope (Southern Spain): Soil surface conditions, runoff and erosion in Southern Spain, Catena, 80, 131-139, 2010.

Ruy, S., Findeling, A., and Chadoeuf, J.: Effect of mulching techniques on plot scale runoff: FDTF modeling and sensitivity analysis, J. Hydrol., 326, 277-294, 2006.

Smets, T., Poesen, J., and Knapen, A.: Spatial scale effects on the effectiveness of organic mulches in reducing soil erosion by water, Earth-Sci. Rev., 89, 1-12, 2008.

Yanosek, K. A., Foltz, R. B., and Dooley, J. H.: Performance assessment of wood strand erosion control materials among varying slopes, soil textures and cover amounts, Journal of Soil Water Conservation, 61, 45-51, 2006. 